\title{
An integrated information management system based DSS for problem solving and decision making in open \& distance learning institutions of India
}

\author{
Pankaj Khanna $^{a^{*}}$ and P.C.Basak
}

${ }^{a}$ Deputy Director, Planning and Development Division, Indira Gandhi National Open University (IGNOU), Maidangarhi, New Delhi 110068, India ${ }^{b}$ Professor of Management, Indira Gandhi National Open University (IGNOU), Maidangarhi, New Delhi 110068, India

\section{H R O N I C L E}

Article history:

Received January 15, 2013

Accepted October 12, 2013

Available online

November 52013

Keywords:

Decision Support System (DSS)

Management Support System

(MSS)

Integrated Information System

Fuzzy theory

Open \& Distance Learning

Institution

\begin{abstract}
A B S T R A C T
An integrated information system based DSS is developed for Open and Distance Learning (ODL) institutions in India. The system has been web structured with the most suitable newly developed modules. A DSS model has been developed for solving semi-structured and unstructured problems including decision making with regard to various programmes and activities operating in the ODLIs. The DSS model designed for problem solving is generally based on quantitative formulas, whereas for problems involving imprecision and uncertainty, a fuzzy theory based DSS is employed. The computer operated system thus developed would help the ODLI management to quickly identify programmes and activities that require immediate attention. It shall also provide guidance for obtaining the most appropriate managerial decisions without any loss of time. As a result, the various subsystems operating in the ODLI are able to administer its activities more efficiently and effectively to enhance the overall performance of the concerned ODL institution to a new level.
\end{abstract}

(C) 2014 Growing Science Ltd. All rights reserved.

\section{Introduction}

The Open and Distance Learning (ODL) system in India serves to the educational needs of millions of its students and is one of the largest education systems in the world. Presently it comprises 14 open universities and about 200 dual mode distance education institutes/centres in the country, offering distance education to about 5 million students. However, it is crucial to properly manage these institutions so as to perform their functions satisfactorily and achieve the goal of providing quality education to their learners. Presently, managing distance educational institution in today's fastchanging world is an enormous challenge for administration and heads of institution. The conflicting pressures of reducing costs on the one side, and providing better and more responsive service to students on the other are major concerns for the management of Open and Distance Learning Institutions (ODLIs). In addition the basic requirement for the satisfactory operation and good

* Corresponding author.

E-mail addresses: pk@ignou.ac.in, khanna.delhi@gmail.com (P. Khanna)

(C) 2014 Growing Science Ltd. All rights reserved.

doi: $10.5267 /$ j.ds1.2013.11.002 
performance of an ODLI is the elimination of failure of processes, services and products. Under such circumstances a good educational system is required whose administration would provide a mean for planning, organizing, controlling and above all preventing failure by making appropriate decision at all levels. Hence it is felt that for successful operation of ODLIs, an efficient Decision Support System (DSS) capable of taking effective and timely decisions pertaining to its various activities and tasks must be operational in these ODLIs.

In recent times, the ODL institutions in India have felt the need of improved information usage and decision making in planning and managing its various activities and tasks so as to enhance its overall performance to a satisfactory level. It may also be mentioned that decisions taken at policy level can be implemented effectively, only if a consistent decision-making support system is already in place, otherwise all decisions taken would go in vain. However sound managerial decisions can be made only with full awareness of the organisation's policies, general conditions and above all with adequate knowledge of management information. In other words a good decision-making system could be realised by employing such a systematically planned system which uses most appropriate and exact information so as to make good decisions. So, such a system for ODL institutions in India, when well designed (by employing most appropriate and adequate information systems) will assist their local managers in effective decision making required for efficient management and successful operation of the concerned ODLI.

However, presently in the ODLIs there are in general separate and individual information systems employed for operating its various functional sub systems such as related to finance, attendance, personnel, courses and students etc. It is realised that to work with them separately is quite tedious, time consuming and inconvenient. At the same time it is observed that many of the functions to be performed in an ODLI are dependent on the same basic data. However lack of integration and coordination among the different subsystems involved, preclude the possibility of such data sharing in an effective way. So the overall benefit of using such information systems separately tends to become only marginal due to such constraints. Whereas, through integration it is possible to design a common dynamic database that can be employed for efficiently planning the various systems including those involved in the process of decision-making in the ODLIs. Also through integration it would be possible to design several related applications through the use of a single integrated information system as this would not only further simplify the interconnections but also reduce the duplication of input.

As such the integrated system will enhance the effectiveness and efficiency of the various application systems operating within the concerned ODLI. In addition the integrated information system is found to play a vital role in the organisational performance of the concerned ODLIs. It is observed by O'brien and Markas (2007), (Laudon \& Laudon, 2007) that such systems create value for the organisation by improving their business processes, products and services. However the integrated information system based DSS shall further improves the efficiency of the organisation's performance by enhancing decision making and improving strategic positioning. In addition, such a DSS while also including the components of knowledge management can help to work out the most satisfying solutions for the current problems; and thus substantially improves the performance evaluation of the business processes and activities involved in the operation of the concerned ODLI.

The need for developing a DSS model based system in ODLIs also transpired from the fact that presently there exists no thorough and comprehensive system in ODLIs for problem solving and decision making as related to various programmes and activities operating in the concerned ODLIs. Also, there is absence of any periodic reviewing process for such programmes. This as a result can lead to delay and mismanagement in the decision making as related to the overall configuration and for improving the quality of the programmes concerned. Moreover a systematic effort as evolved in the DSS proposed would provide an opportunity for self-reflection and consideration of the 
programmes' direction for the future. So, in this study, a prototype of the integrated information systems based DSS model has been developed for effective decision-making. As such the efficiency for managerial working of the ODLIs would improve to a significantly satisfactory level.

\section{Information Management Systems in ODLIs and their Integration}

For developing an integrated information system based DSS model for ODLIs, it is imperative to initially review the hierarchy of information management systems and subsequently their integration in ODLIs. To accomplish this, an information management system for ODL institutions is firstly developed and documented. The group of information systems evolved as such would be actively involved in the educational planning and decision making as related to the concerned ODLI.

In an early study related to information management systems, three basic types of information systems have been identified by Kozar (1989); which include operational, decision support and communication systems. As the names imply, these systems support operational tasks, decisionmaking and communication activities involved in the concerned organisations. With the passage of time and advancement in ICT(Information and Communication Technology), an increasing interest has been shown by many research analysts (Martin, 1990; Dick James et al., 1991; Helden,1994; Laudan \& Laudan, 1999) towards the development and further improvement in these systems so as to meet the current and immediate needs of the concerned organisations. However to meet the current and immediate needs of the present ODLIs associated with DES of India, it is desired to initiate efforts for bringing about related improvements into the existing educational systems pertaining to the ODLIs.

As such while managing information in present day educational organisations an information management system is articulated which depicts the hierarchy of information systems applicable also in the ODLIs. These systems which are involved for educational planning in an ODL institution varies from basic information supply system to an expert system for automated decision making. However for properly managing an ODLI it is highly desired to establish an information system based model support system.

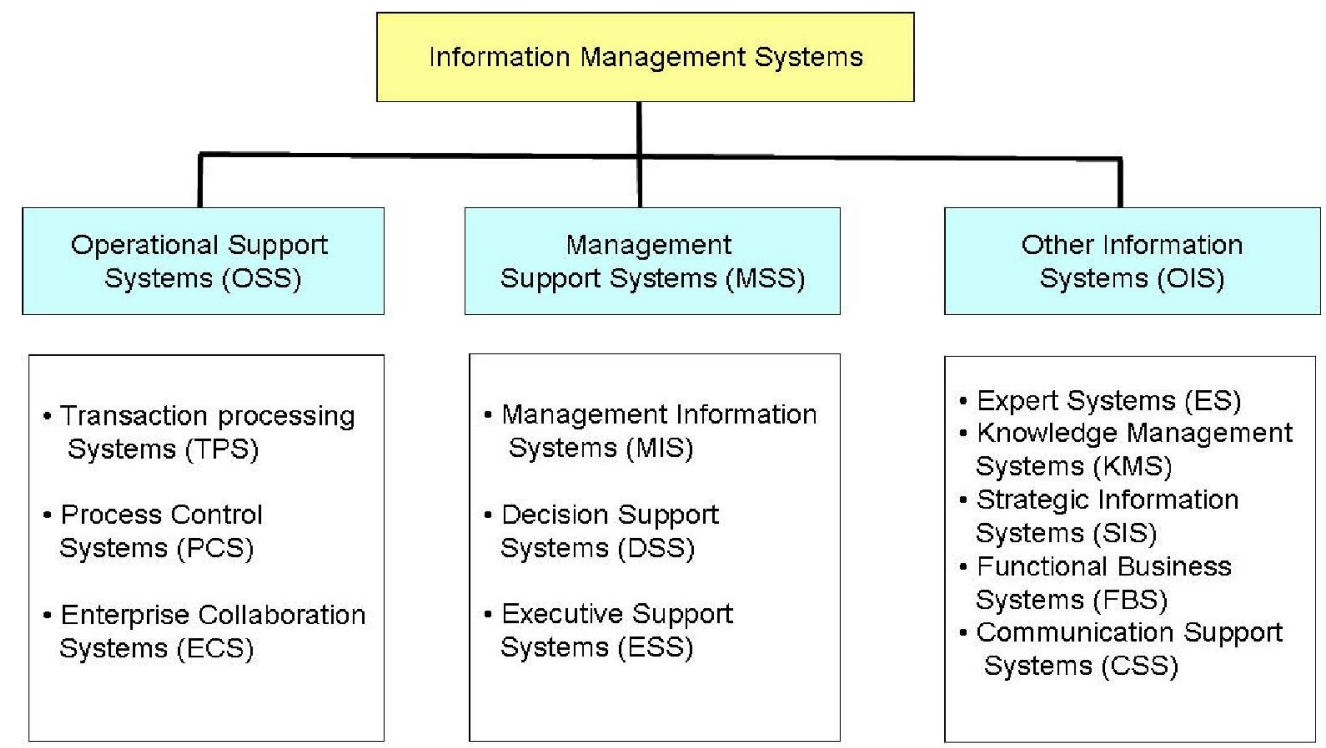

Modified from: Laudan and Laudan(1999)

Fig. 1. Hierarchy of Information Systems applicable to ODL institution 
It may be noted that in general the various information systems in an organisation do not operate independently; rather, there are interdependencies between these systems. They exchange data and information with one another. A review of Fig. 1 illustrates that in an ODL institution, TPS are a major source of data and producer of information for other systems, especially MIS and DSS whereas ESS is primarily a recipient of data from lower level systems such as MIS and DSS. Considering the interdependencies among various information systems involved and to enhance efficiency the different systems in an organisation are preferred to be integrated. In other words the information needs of the various functional areas and at various organisational levels in an ODLI, would be met effectively by the use of an integrated system.

\subsection{Basic structure of the proposed Integrated Information Management System}

While creating the basic structure of the integrated information system for ODL institutions, the various information systems involved are needed to be coordinated into an integrated system. The integration of these systems is achieved by organising them into a hierarchical structure which is determined by the functions of the particular department in the concerned ODLI. As already indicated, the functions in an ODL institution can be divided into three basic levels i.e. operational, management functions and strategic planning functions. This functional structure as given in Fig. 2 forms the basis of the proposed integrated information system, consisting of an:

- Operational system, in the form of modules for routine decision-making.

- Institutional management system; for management decisions.

- Strategic planning system; for monitoring development and planning future development.

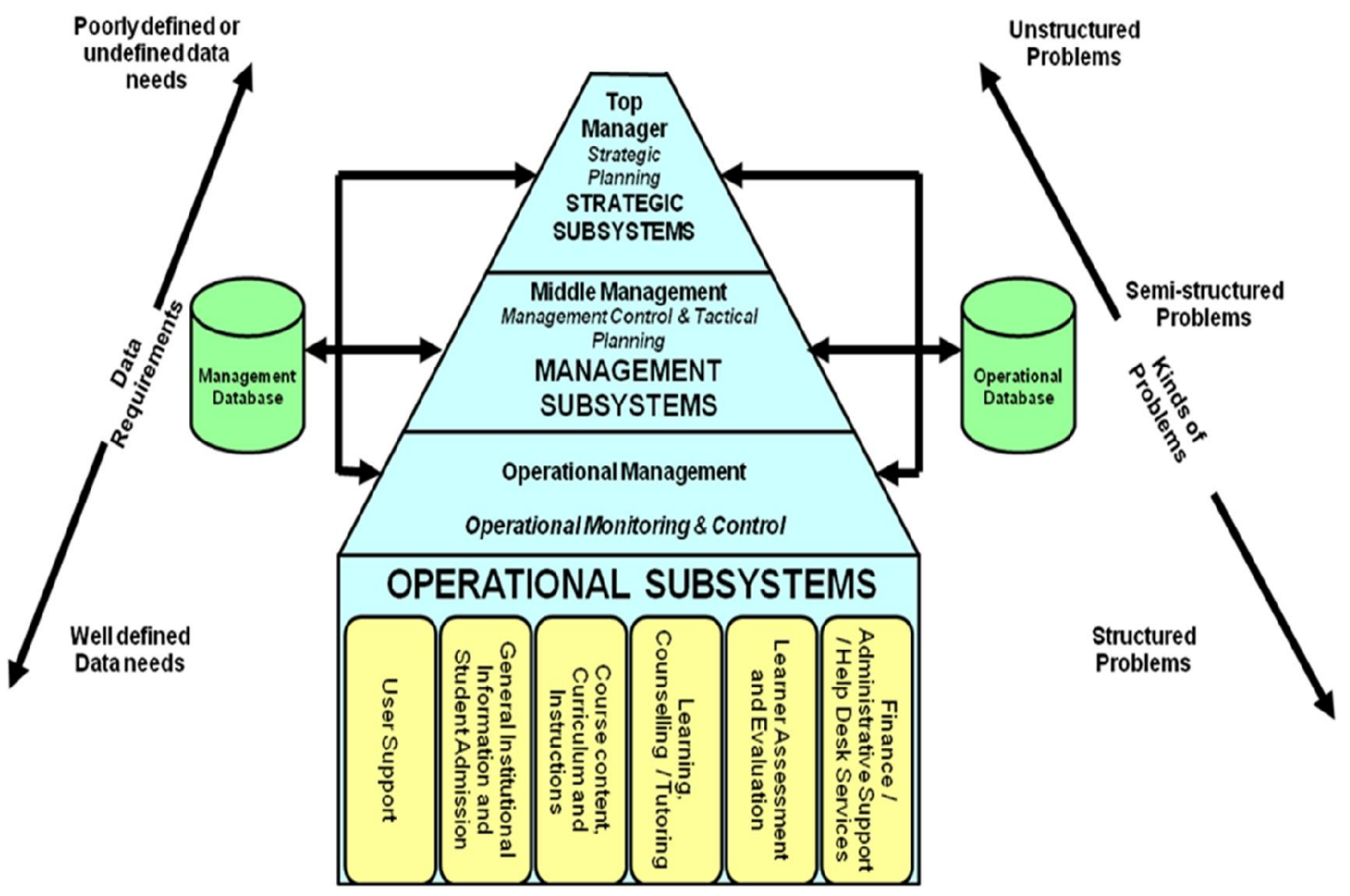

Fig. 2. Basic structure of the Integrated Information System

Fig. 2 illustrates the basic structure of the integrated information systems while indicating the various subsystems (operational, managerial and strategic) as well as the information flow between them and 
the databases. It also depicts the data requirements and kinds of problems being encountered during operation and management of the concerned ODL institution. For strategic subsystems the data needs are minimal and cater to mainly unstructured problems, whereas for operational subsystems, the data requirements are well defined and these cater mainly to structured problems.

\section{Integrated Information System based DSS}

To accomplish the task of decision making as related to the various distance learning programmes and activities in the ODLIs, an integrated information system based decision-making support system is established. The design of the system is such that it would be able to integrate data from different sources involved such as students admissions/enrolments; students attendance, retention, completion and placements; students counselling and tutoring, quality of instruction, revenue resources, costs, labour market, students/employers feedback and other sources of course quality etc.

In general, the main components of the DSS to be set up in an organisation are the DSS Databases, the DSS software systems and the user interface (Boreisha \& Myronovych, 2007). As such the DSS system designed in the ODLIs is mainly based on making the use of relevant Data-warehouses, Model Based Management System, Knowledge Based Management System and the User interface etc. However, it is very much desired that the different components in the DSS designed for ODLIs should have web interfaces so as to take advantages of graphic displays, improved interactivity and ease of use. So web based decision support system is designed with the aim of developing this system online with latest available software packages.

\subsection{Web Structure for the Decision Support System}

The integrated information system based decision support system designed for the ODL institutions is component and module based. While designing such a system, its main constituents are first laid out. Then the process, through which the general system can be implemented, is outlined. As such the integrated information system based DSS (see Figure 1.3) makes use of three main components, which include relational database management system, model base multidimensional data management system and knowledge base (Turban and Aronson,2003). For practical reasons each of the main distribute database may contain a number of smaller databases. A brief description of the main database and other management systems is given as follows:

i) Relational Database Management System: The relational database management system (RDBMS) includes databases which contain relevant data for the situation and is managed by a series of components and modules involving the associated software. The data management system is interconnected with the central data warehouse, a repository for the institution's relevant web based system data. This database is basically a collection of records in a tabular form stored from a number of current activities and programmes operating in the concerned ODLI. As such it is a data warehouse in form of a central repository that integrates the institutional data sources and maintains the overall record of institutional data. Specifically, this system emphasizes access to and manipulation of databases of structured data in general and internal and/or external institutional data in particular. However relational databases accessed through query and basic programming techniques provide an elementary level of functionality, whereas employing Online analytical processing (OLAP) provides the diagnostic functionality for decision making linked with the large collections of institutional data. However various document databases can also be accessed through WWW (World Wide Web) associated with this system. Examples of such documents accessed are institution policy, procedures, pre-enrolment and post 
enrolment requirements, programme brouchers, minutes of statutory authorities meetings, etc.

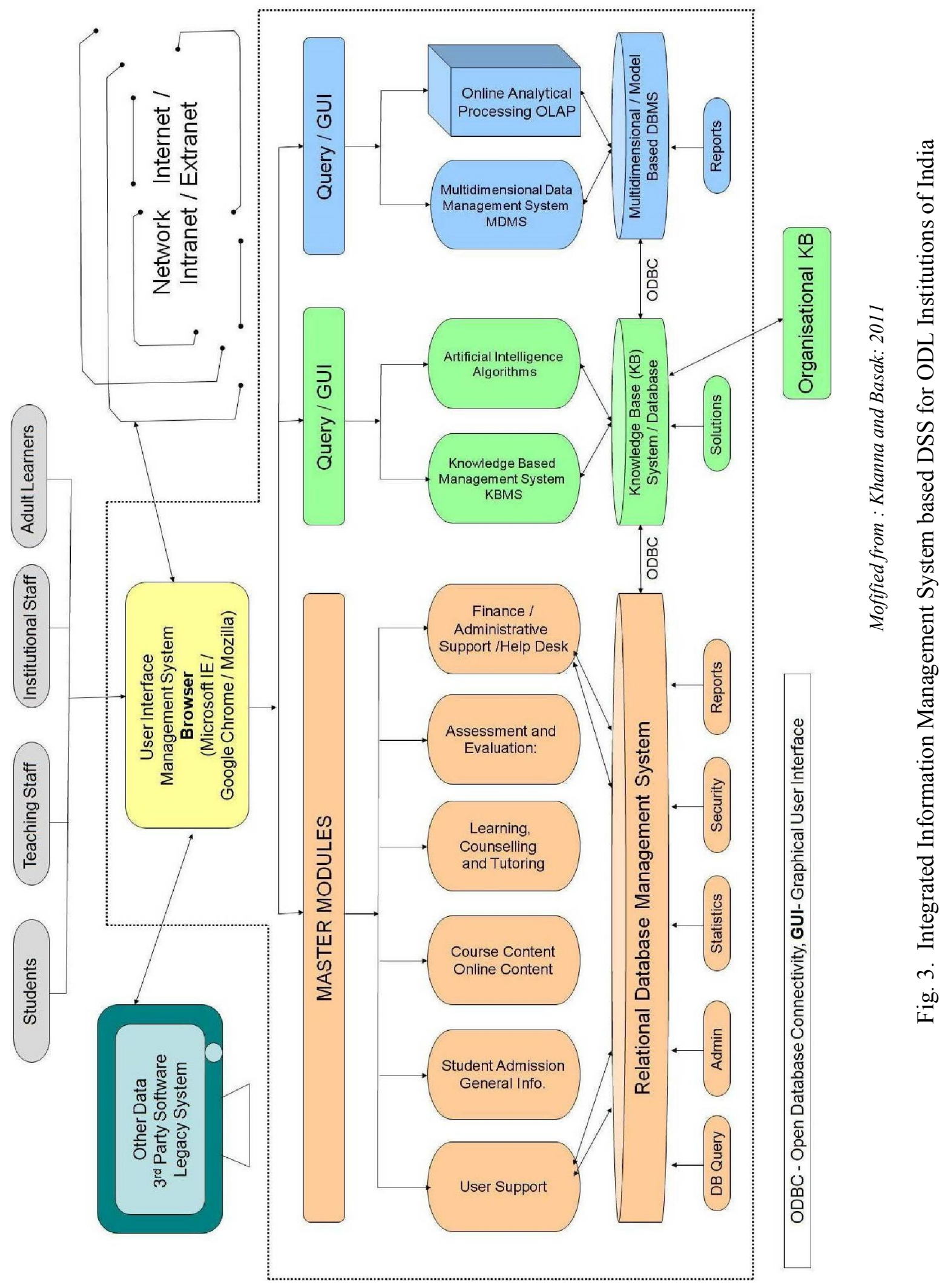


ii) Model Based Management System: The Model Base Management System (MBMS) is in the form of a software package and includes educational, managerial and other qualitative models that provide the system's analytical capabilities and appropriate software management. Modelling languages for building custom models also form a part of this system. This system is further connected to the institution's external storage of models. As the name implies, such system emphasizes access to and manipulation of the model employed. It is in general constituted of the DSS software mainly in the form of modules that are employed for data analysis. It may also contain various OLAP modules and data mining tools. A collection of statistical and analytical models is also provided to the DSS users. However, simple statistical and analytical tools provide an elementary level of functionality whereas, some OLAP systems can allow complex analysis of data which as such provide a higher level of functionality (Boreisha and Myronovych, 2008). A hybrid subsystem employed emphasizes both the use of decision models and communication so as to facilitate the solutions of problems by decision makers. Thus this system on the whole provides communication, processes, system(s) document scheduling and its sharing which as such enhances group efficiency for decision making activities.

iii) Knowledge Based Management System: The knowledge base management system (KBMS) consists of one or more intelligent systems and provides the necessary execution and integration of the associated systems comprising the integrated information system. As such this system supports other sub-systems and provides intelligence for augmenting the process involved in the system of student support services. This is further interconnected with organisation's knowledge depository, which is also called organisational KB (knowledge base). Expert Systems are thus evolved to acquire expertise that consists of knowledge of a particular domain and expertise for solving the problems by applying AI algorithms. This system also provides the expertise of data mining, which is a class of analytical application that search for hidden patterns in a database by surfing through large amounts of data so as to produce data content relationships. On the whole, data mining is involved in the automated discovery of previously unknown patterns and relationships including prediction of trends and behaviours. Thus using knowledge systems and data mining along with databases and online analytical processing, the proper knowledge can be found out, analyzed and put in the proper context.

iv) User Interface Sub-system and the Organisational Knowledge Base: Through this system, the user would be able to communicate and command the Web-based system. The DSS User Interface permits easy interaction between users and the DSS software modules. Using this system a user can enter and save his profile, input criteria for a new query, run different queries and display results. As such, the user is able to communicate with and command the Web-based DSS. However, the dialog manager as such would be in-charge for the information visualization.

The above mentioned components would constitute the DSS application system and would be connected to the corporate Intranet, to an Extranet or to the Internet. Finally, access to the Intranet, Extranet or Internet and other computer based network systems would permit the DSS to join with other function specific subsystems including the TPS etc. (see Figure $1.3)$. 
So far as the operational aspects of the web enabled DSS are concerned, it is mentioned that the decision support system is initially developed on the World Wide Web (see Fig. 4) and the concerned ODL institute provides the services through a web server accessing both the institute's data warehouse and potentially legacy system. The users are able to access services through any web browser connected to the Internet.

These browsers allow navigating in the world of Web documents also called pages. However, when the URL (Universal Resources Locator) address of the page is typed in the browser, the browser would search the document and would make it available on the computer screen. The operation of the decision making system can be started by loading the various configuration files related to a particular application and initializing the associated database for the application before handling a user's request. Once the DSS system is initialized, users can enter their own profiles related to the particular query in the user-interface. It is then forwarded to the appropriate modules and after due processing, the query results are displayed to the users.

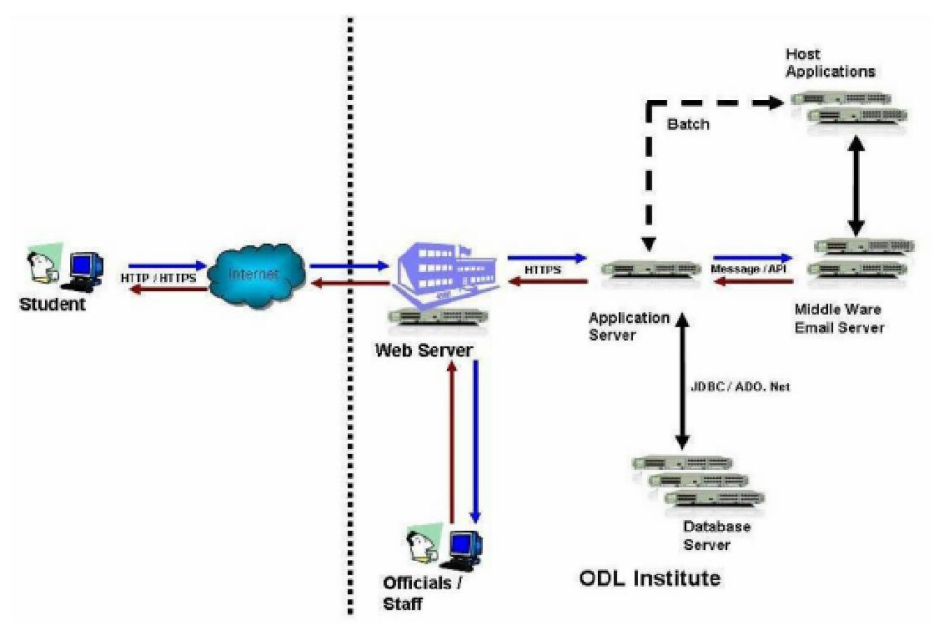

Source: Khanna and Basak:

Fig. 4. Web infrastructure architecture for integrated information system based DSS in an ODLI

\section{Problem Solving and Decision making in ODLIs}

A DSS model is developed which is employed in the web based system (Fig. 3) for problem solving and decision making as related to the various activities and tasks pertaining to the concerned ODLIs. This model in association with the web based system functions as an information analysis decision making system which integrates information from various different sources involved. The information thus gathered from such sources when applied into the DSS model would subsequently enable us to produce a coherent analysis report. The further critical examination of this analysis report would lead to the final management decision. However it is reiterated that the overall process of rational decision making with regard to the problem solving such as performance evaluation of various programmes in the ODLI, is mainly concerned with defining the problem, creating programme criteria, scoring programme against the criteria, eliciting programme reports and computing the optimal managerial decisions.

It is well known that the different organisational levels (i.e. strategic, managerial and operational) in an ODLI have different decision making requirements. Decisions can be structured, semi-structured or unstructured. The structured decisions are clustered at the lowest i.e. operation systems level and 
unstructured at the top or strategic level of the organisation. As such the continuum of decision making process in an ODLI ranges from highly structured (sometimes call programmed) to highly unstructured (non-programme) decisions. Structured processes are routine for which standard solutions are available. Unstructured processes are fuzzy complex problems for which there are no clear cut solutions. However for each type of these problems, solution method can be developed through the use of quantitative formulas and fuzzy theory based method respectively. As such in the present study; the following two types of decision making systems have been considered:

Type-1: The first type of the decision making system has been developed through the use of quantitative formulas which can be employed for monitoring and assessing the performance and decision making as related to the various programmes and activities involved during the operation and management of the concerned ODLI.

Type-2: However in some cases the evaluation of academic performance and decision making may consist of such components which are based on imprecise and/or uncertain data. Such situations occur mainly in unstructured problem domains or in some semi-structured domains. Hence for problem solving and decision making under such circumstances, a fuzzy theory based method has been developed.

\subsection{Type-1: A DSS Model for Problem Solving and Decision Making}

The design of a DSS model developed for ODL institutions is based on weighting model (Carkhuff \& Anthony, 1981). A DSS model framework illustrating rational decision making while evaluating the performance of various programmes /activities in ODLIs has been given in Fig. 5. In this model the key performance indicators /criteria $\left(\mathrm{P}_{1}, \mathrm{P}_{2} \ldots \ldots . \mathrm{P}_{\mathrm{m}}\right)$ involved in the performance evaluation of the programme / activity under study are first identified and then subsequently assigned a relative weight $\left(\mathrm{W}_{1} \%, \mathrm{~W}_{2} \%, \ldots \ldots . . \mathrm{W}_{\mathrm{m}} \%\right)$ depending upon the impact of that indicator / criteria on the performance of the programme /activity under evaluation. Various attributes associated with each indicator /criteria and then identified. Different alternatives as related to the each attribute are then collected and their corresponding values are determined depending upon the performance level of that factor involved in this process. These values are further weighted in accordance with the individual's perception on the worth of that factor involved in the overall decision making process. This process is carried out for each programme individually. Finally all the programmes(under study) are graded / rank ordered in five categories (excellent, good, average, marginal and poor) according to their overall scores obtained which are based on the cumulative weighting of their scales.

\subsubsection{Evaluation and Weighting for determining Performance Value}

Once these scores have been determined, a weighted average of the score will be calculated. These weighted scores thus developed by the evaluators would reflect the importance of variables involved in the performance evaluation of the programme on the case-to-case basis with regard to the specific requirements of the ODL institutions concerned.

Table 1

Calculation of weighted average of the score

\begin{tabular}{rcccc}
\hline S.No. & $\begin{array}{c}\text { Variable Performance } \\
\text { Indicators / Programme Criteria }\end{array}$ & $\begin{array}{c}\text { Weight } \\
\text { (points) } \%\end{array}$ & $\begin{array}{c}\text { Rating } \\
\text { Score }\end{array}$ & Product \\
\hline 1. & $\mathrm{P}_{1}$ & $\mathrm{~W}_{1}$ & $\mathrm{X}_{1}$ & $\mathrm{~W}_{1} \mathrm{X}_{1}$ \\
\hline 2. & $\mathrm{P}_{2}$ & $\mathrm{~W}_{2}$ & $\mathrm{X}_{2}$ & $\mathrm{~W}_{2} \mathrm{X}_{2}$ \\
$\mid$ & $\mid$ & $\mid$ & $\mid$ & $\mid$ \\
$\mathrm{M}$ & Any other, not covered above: $\mathrm{P}_{\mathrm{m}}$ & $\mathrm{W}_{\mathrm{m}}$ & $\mathrm{X}_{\mathrm{m}}$ & $\mathrm{W}_{\mathrm{m}} \mathrm{X}_{\mathrm{m}}$ \\
\hline
\end{tabular}




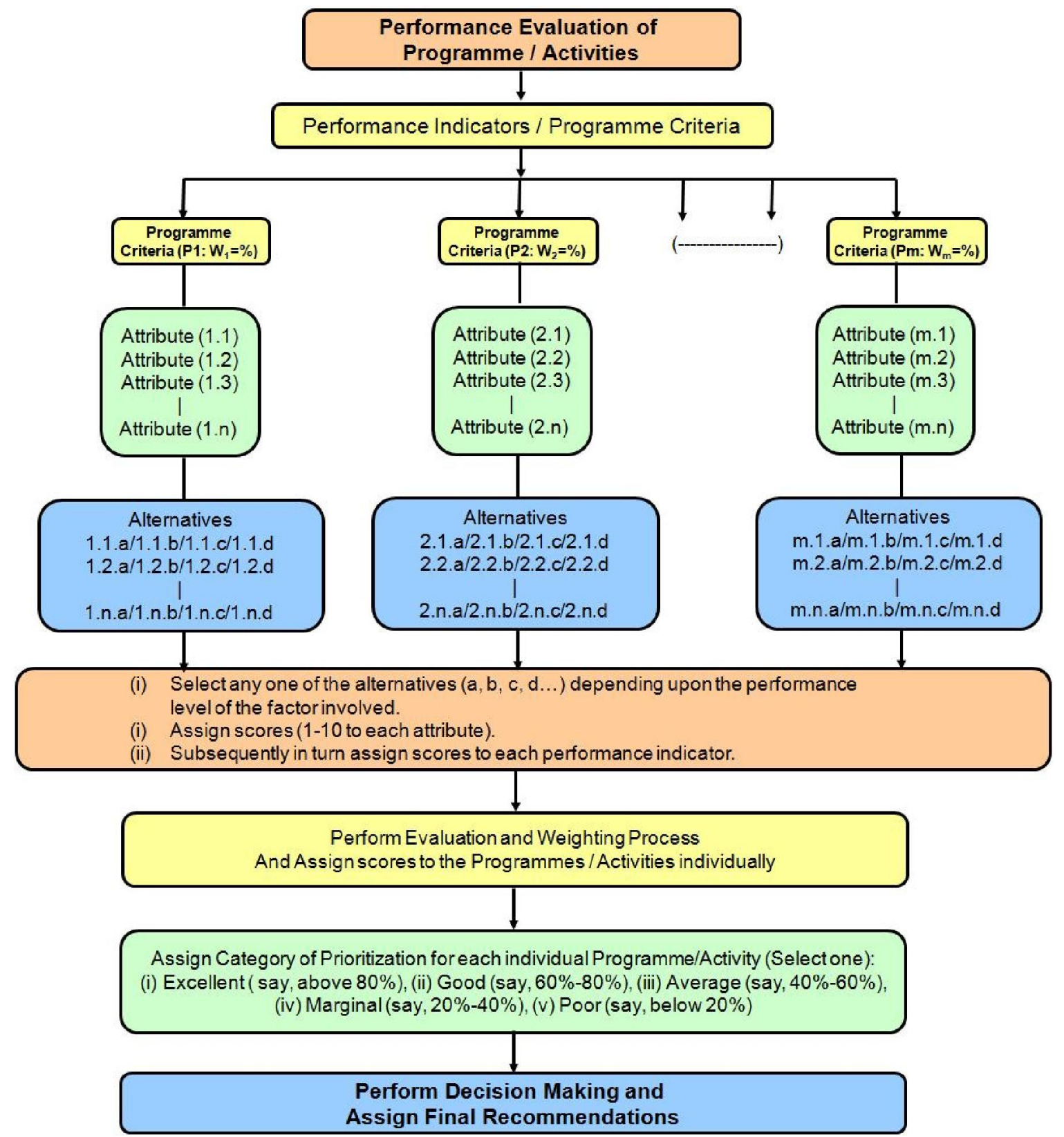

$W_{m} \%$ - relative weightage for programme/ activity criteria no. $m$

$$
W_{1}+W_{2} \ldots \ldots . W_{m-1}+W_{m}=100
$$

m: number of programme criteria associated with a programme /activity.

n: number of attributes within a programme/activity criteria

Fig. 5. A DSS model framework for evaluating the performance of Programmes / Activities in ODLIs

Total scores $=\sum_{j=1}^{m} W_{j} X_{j}$ and Performance value $\mathrm{P}$ in $\%$ is $\mathrm{P}=\frac{\sum_{j=1}^{m} W_{j} X_{j}}{W_{\max } X_{\max }} \times 100$. In addition, $W_{\max }=W_{1}+W_{2}+W_{3}+\cdots$ and $X_{\max }$ is the maximum value assigned to rating score. 
On the basis of program response with regard to its performance each of these variables will be given a rating score, based in a scale of (say, 1-10). With 1(one) indicating little appropriate evidence and 10 indicating conclusive evidence. (If no pertinent information is available a 0 will be used). As such hypothetically it may be mentioned that a programme which is scoring a maximum of 10 on each criteria i.e. $\mathrm{X}_{\max }=10$, would have a maximum total score of 1000 . As a specimen, a list of the proposed measurement variables with regard to various performance indicators /Programme criteria has been presented at Annexure-A.

Thus, once all the programmes have been rated, the evaluators will be able to use the ratings to decide and guide their rankings and subsequent decision making along with future strategies to be adopted for the betterment / enrichment of the programmes concerned.

\subsection{Type-2: Fuzzy Theory based DSS}

A schematic view of the proposed fuzzy based decision making system that can be employed for performance evaluation of various programmes / activities in an ODLI has been given in Fig. 6 .

The proposed fuzzy theory based method is comprised of three stages; an input stage, a processing stage and an output stage. The input stage would map inputs to the appropriate membership functions and truth values, while subsequently also employing the fuzzification process so as to generate fuzzy input values. The processing stage would invoke an appropriate set of logic rules; generate a result for each rule, and then combines these results through an inference mechanism so as to generate fuzzy output values. Finally, the output stage would convert the fuzzy output obtained from combined result, back into a specific control output value by the process of defuzzification, so as to generate the final decision and the required performance value. The process of defuzzification and determination of performance value is given as below:

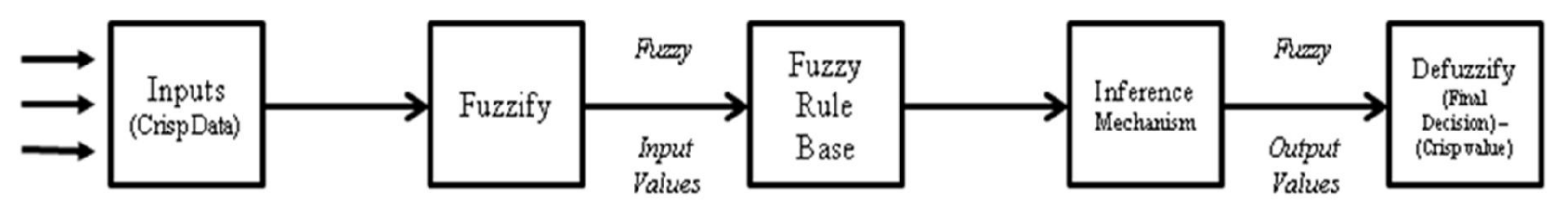

(Source: Lorestani et.al., 2006)

Fig. 6. A Schematic view of Fuzzy logic based decision making system

\subsubsection{Defuzzification and Determination of Performance Value}

A number of defuzzification methods such as Center of Gravity $(\mathrm{CoG})$ also known as Centroid, mean of maximum and first of maximum exists (Zimmermann, 2001). The CoG method is adopted as this method is most popular and also it is more accurate in representing fuzzy sets of any shape (Cochran \& Chen, 2005; Padhy, 2005).

A Centroid is defined by summing all the moments (location time mass) around the centre of gravity and equating the sum to zero. So if $X_{C}$ is the centre of gravity, $X_{i}$ is the location of each mass, $M_{i}$ is each mass, this gives:

$\left(X_{1}-X_{c}\right) \times M_{1}+\left(X_{2}-X_{c}\right) \times M_{2}+\cdots+\left(X_{n}-X_{c}\right) \times M_{n}=0$

Therefore, 


$$
X_{c}=\frac{X_{1} \times M_{1}+\cdots+X_{n} \times M_{n}}{M_{1}+\cdots+M_{n}} .
$$

However in the present study, if the mass corresponds to the truth values $\mu_{i}$ and the location of masses corresponds to the values of corresponding output variables $z_{i}$, then the centroid computation would yield:

$\mu_{c}=\frac{\sum_{i=1}^{n} \mu_{i} \times z_{i}}{\sum_{i=1}^{n} \mu_{i}}$

After completing the above computations, the fuzzy Performance value is obtained by the centre of area (centroid) technique as mentioned above. The Performance value P (Padhy, 2005), is calculated from the formula as given below:

$$
P=\frac{\sum_{i=1}^{n} \mu_{i} \times z_{i}}{\sum_{i=1}^{n} \mu_{i}}
$$

\subsection{Assigning the Grade Category to different programmes/activities}

Depending upon the overall scores obtained by the programme under study from the evaluators, it is assigned a ranking and subsequently decision making regarding the future of the programme concerned. The proposed ranking list is as follows,

\section{Table 2}

\begin{tabular}{|c|c|c|c|}
\hline S.No. & Grade Number & Grade Nomenclature & Performance Value obtained (\%) \\
\hline 1. & $1^{\mathrm{st}}$ & Excellent & Above $80 \%$ \\
\hline 2. & $2^{\text {nd }}$ & Good & $(60-80) \%$ \\
\hline 3. & $3^{\text {rd }}$ & Average & $(40-60) \%$ \\
\hline 4. & $4^{\text {th }}$ & Marginal & $(20-40) \%$ \\
\hline 5. & $5^{\text {th }}$ & Poor & Below $20 \%$ \\
\hline
\end{tabular}

Ranking List

\subsection{Decision making for the programmes under study}

i) 1st Grade: Programmes receiving high overall programme scores i.e. $80 \%$ and above are listed under this category. Programmes/activities under this category must be encouraged and further strengthened with more resources and investments for highquality expansion of the ODL institution.

ii) 2nd Grade: Programmes under this category generally receive medium to high (i.e. above $60 \%$ and below $80 \%$ ) overall programme scores. Support to these programmes/activities and encouragement with resources is essential to maintain the academic performance of the concerned ODL institution.

iii) 3rd Grade: Programmes assigned to this category generally receive medium to low (i.e. above $40 \%$ and below $60 \%$ ) overall programme scores. Programmes/activities with these grades require restructuring curriculum and counselling with a view for reallocation of resources in terms of their realistic viability for the concerned ODL institution. 
iv) 4th Grade: Programmes assigned to this category generally receive low (i.e. above $20 \%$ and below $40 \%$ ) overall programme scores. Extra allocated resources may be shifted to other programmes/activities to enhance the academic performance of the university. Minimal support may be provided to the programmes/activities listed under this grade.

v) 5th Grade: Programmes assigned to this category receive very low (i.e. upto $20 \%$ ) overall programme scores. Programmes/activities under this category need urgent attention for its rationalization. These programmes /activities needs to be adequately assessed through a careful review for their potential to contribute to the academic performance of the ODL institution in the future. In-case review findings are negative, resource allocated to the programmes/activities listed under this grade may be shifted to other programmes/activities.

\section{Concluding Remarks}

An integrated information management system based DSS is designed for ODL institutions of India. The decision support system thus developed is web based and facilitates problem solving for unstructured and semi-structured domains related to the ODLI programmes and activities. It would help ODLI management to quickly identify programmes and activities needing attention, provide documentation to demonstrate programmes' quality and justify management decisions. The overall result of using such a DSS in ODLI includes higher decision quality, improved communication, cost reduction, increased productivity, time savings and enhanced end user's satisfaction. It is inferred that the DSS based model system thus developed at ODLIs would facilitate quick and timely decision making for long term planning, short term planning, budgeting and other educational planning in the concerned ODLI. As such the various subsystems operating in the ODLIs would be able to administer its activities more efficiently and effectively so as to enhance the overall performance of the concerned ODLI to a new level.

\section{Acknowledgements}

The authors would like to very much thank the following organisations and the associated persons whose generous works have helped us to undertake and prepare this article:

- IGNOU, Distance Education Council and Egyankosh (http://www.ignou.ac.in/), (http://www.dec.ac.in/) and (http://www.egyankosh.ac.in/)

- Indiana Commission for Higher Education (http://www.in.gov/che/ and http://www.indstate.edu/acad-aff/doc/program_prioritization/framework.pdf).

- Indiana State University, 200 North Seventh Street, Terre Haute, Indiana, USA (www.indstate.edu/academicaffairs/program_prioritization/report.doc)

- Institute of Electrical and Electronics Engineers - IEEE Xplore (http://ieeexplore.ieee.org)

- National Knowledge Commission of India (http://www.knowledgecommission.gov.in/)

- Press Information Bureau of India (http://pib.nic.in/)

- UNESCO (http://www.unesco.org/new/en/unesco/ )

- Western Carolina University (http://www.wcu.edu and http:// http://www.wcu.edu/WebFiles/ProgramPrioritizationReportPart1.pdf)

\section{Trademark Information:}

Java, JDBC, ADO.Net, Dot Net etc. anywhere in the article are trademarks or registered trademarks of Sun Micrososytems, Inc., MicroSoft Ltd. and IBM. All other trademarks are owned by their respective companies. 


\section{References}

Boreisha,Y., \& Myronovych, O. (2007). Web-Based Decision Support System in Knowledge Management and Education, Proc. International Conference on Information and Knowledge Engineering, Las Vegas, USA, 11-17.

Boreisha,Y., \& Myronovych, O. (2008). Web-Based Decision Support Systems as Knowledge Repositories for Knowledge Management Systems, Ubiquitous Computing and Communication Journal, 3(2), 104-111.

Carkhuff, R.R., \& Antony, W.A. (1981). The Skills of helping. Human Resource Development Press Inc. Amherst, MA.

Cochran, J.K., \& Chen, H. (2005). Fuzzy multi-criteria selection of object oriented simulation software for production system analysis. Computers and Operations Research, 32, 153-168.

Dick, J.C., Mitchell, D.E., \& Hecht, J.B. (1991). Design of a Management Information System for California's Regional Occupational Centres and Programs. University of California, USA.

IGNOU (2005). e-GyanKosh, a National Digital Knowledge Repository, Indira Gandhi National Open University, New Delhi, India. Downloaded from http://www.egyankosh.ac.in

Khanna, P., \& Basak, P.C. (2010). A Comprehensive Web Based Student Support System for ODL Institutions of India. Paper presented in the Sixth Pan Commonwealth Forum on Open Learning (PCF6), Kochi, India.

Khanna, P., \& Basak, P. C. (2011). An Integrated Web-based Information System for Open and Distance Learning Institutions in India. The Journal of Information Technology Impact (JITI), 11(2), 153-168.

Kozar, K.A. (1989). Humanized Information Systems: Analysis and Design. McGraw Hill, New York.

Laudon K.C., \& Laudon J. P. (1999). Management Information Systems: Organization and Technology. (4 ${ }^{\text {th }}$ Ed.). Prentice Hall of India, New Delhi-1 10001.

Laudon, K.C., \& Laudon J.P. (2007). Essentials of Management Information Systems: Managing The Digital Form, $6^{\text {th }}$ Ed. New Jersey, USA: Prentice Hall.

Lorestani, A.N., Omid, M., Shooraki, S.B., Borghei A.M., \& Tabatabacfar A. (2006). Design and evaluation of a fuzzy logic based decision support system for grading of golden delicious Apples. International Journal of Agriculture and Biology, Vol.8, No.4, 440-444.

Martin, J. (1990). Introduction to Information Engineering. Prentice-Hall, Englewood cliffs, N.J.(USA).

O'Brien, J.A., \& Marakas, G.M. (2007). Enterprise Information Systems, $13^{\text {th }}$ Ed. Boston, USA: McGraw-Hill International.

O’Brien, J.A., \& Masizana A. (2004). Decision Support for Information Systems. $13^{\text {th }}$ Ed., Boston, USA: McGraw Hill International.

Padhy N.P. (2005). Artificial Intelligence and Intelligent System. Oxford University Press, New Delhi.

Turban, E., \& Aronson, J.E. (2003). Decision Support Systems and Intelligent Systems. Pearson Education Pvt. Ltd.

Uzoka, F.M.E. (2009). Fuzzy-expert system for cost benefit analysis of enterprise information systems: A Framework. International Journal on Computer Science and Engineering, 1(3), 254262.

Van Helden, P. (1994). An integrated information system for urban land use management. Pretoria: URISA, p483-495.

Retrieved from http://libraries.maine.edu/Spatial/gisweb/spatdb/urisa/ur94043.html (Jan. 2012).

Zadeh, L. A. (1965). Fuzzy Sets. Information and Control, 165, 8(3) 338-353.

Zimmermann, H.J.(2001). Fuzzy Set Theory and its Applications. 3rd ed. P435. Kumer Academic Publishers, Boston MA. 


\section{Annexure: A}

The experimental variables which were generated from literature and involved in the performance evaluation of various programmes /activities in ODLIs are as follows:

\section{VISION AND MISSION}

Variables related to Vision, Mission, Act and Statues

- Are the goals, vision, legislative act, statutes being revised periodically based on the inputs received from various stakeholders?

- Any workshop organised or committee formed for its revision?

- How many affiliations made with other institutions at national /international level?

- What is status of current relationships with external partner institutions?

- Do the academic support required to meet Vision of the University adequate?

- Steps taken by the ODLI to ensure that it is financially self sustaining with status of utilization of plan and non-plan funds allocated for the development of the activity and the outcome thereof?

\section{ACCOUNTABILITY AND FUNCTIONS}

Variables related to Organisation, accountability and priorities

- Whether the ODLI has any mechanism to monitor that the functions are being performed as per legislative or regulatory rules and regulations of the law of land?

- Is there any report for its violations that took place in the past or lessons learnt from it?

- Have the new programme visualised the future employment openings expected for the next two-three years?

- Have the target groups been defined?

- Have the learning Outcomes and its accountability metrics developed for the programmes /activities?

- Is the UGC approved curriculum available for the proposed course / programme?

- Have Need Assessment been properly coordinated and Student availability is ensured, once the New Programme is launched.

- Do the University have a standard evaluation methodology for similar type of university programmes i.e. for Bachelor or Masters Degree programmes?

- Do the University has a policy to withdrawn or close programme /activities, where the enrolments are low and do not qualify to continue the minimum enrolment standards of University? Number of programmes / activities withdrawn in the last 2-years. 
QUALITY (PROGRAMMES /ACTIVITIES)

Variables related to Learning Materials, Counseling, Support Centres and Tutoring

- Have the structure and format of each course with SLMs have been defined as per UGC model curriculum?

- What is the pedagogical effectiveness of the SLMs?

- Which media (Online / Audi-Video, Multimedia etc.) is appropriate for delivery of the programmes?

- Whether the established Study centres have the required infrastructure as per the programme requirement?

- Whether the Academic Counsellors has the clarity on their role, timings/duration of learning sessions and type of interactions to be done with the learner?

- Whether the Academic Counsellors has the required qualification and experience in SLM, audio-video, teleconferencing and delivery mechanism?

- Whether the Academic Counsellors has been appropriately trained for the new programme and its delivery mechanism?

- How many workshops have been organised? What is the feedback and suggestions of participants?

- Have the Programme wise accreditation been completed for the ODLI?

\begin{tabular}{|l|l|}
\hline OUTCOME & \\
\hline Variables related to Learner Assessment, evaluation and termination \\
- & Is the assessment formative as well as summative? \\
- & Is the grading and evaluation methodology is as per programme \\
& requirements and have been complied with or last minute changes \\
& were made in it? \\
- & Whether placement services are available for the pass-outs? \\
- & What is the external recognition of the learners to get good \\
& employment?
\end{tabular}

\section{COSTS/REVENUE}

Variables related to Finance and other Services including Help Desk Services

- Do we have necessary financial resources to begin and sustain this programme?

- What is the Student Academic Counsellor ratio at the Study Centre for practical oriented courses?

- Have we calculated the cost per credit?

- Have we calculated the cost of development of SLMs?

- What are the investments made in fixed deposits and interest accrued from it?

- Have the help desk services established at the Regional, Study centres etc. with their networking to the headquarters for up-to-date information to the students? 